\section{BRAZIULIAN JOURNAL \\ OF MEDICAL AND BIOLOGICAL RESHARCH}

www.bjournal.com.br
ISSN 0100-879X

Volume 43 (11) 1010-1134 November 2010

BIOMEDICAL SCIENCES

AND

CLINICAL INVESTIGATION

Braz J Med Biol Res, November 2010, Volume 43(11) 1116-1122

doi: 10.1590/S0100-879X2010007500103

Prognosis of colorectal cancer with liver metastasis: value of a prognostic index

Y. Wang, Y.F. Liu, Y. Cheng, D.H. Yi, P. Li, W.Q. Song, D.Z. Fu and X. Wang

The Brazilian Journal of Medical and Biological Research is partially financed by

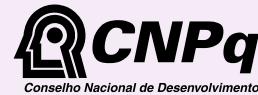

Ministério da Ciência e Tecnologia

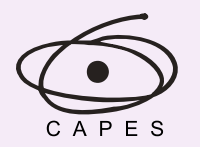

Ministério da Educação

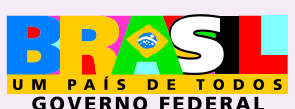

GOVERNO FEDERAL

\section{DFAPESP}

Institutional S ponsors $\oplus$ SHIMADZU
Hotsite of proteomics metabolomics developped by: 


\title{
Prognosis of colorectal cancer with liver metastasis: value of a prognostic index
}

\author{
Y. Wang ${ }^{1,2}$, Y.F. Liu ${ }^{1}$, Y. Cheng ${ }^{1}$, D.H. Yi ${ }^{1}$, P. Li ${ }^{1}$, W.Q. Song ${ }^{1}$, \\ D.Z. Fu ${ }^{1}$ and $\mathrm{X}$. Wang ${ }^{1}$ \\ ${ }^{1}$ Department of General Surgery, The First Hospital of China Medical University, \\ Shen Yang, Liao Ning Province, China \\ 2Department of Surgery, Shen Zhou Hospital, Shen Yang Medical College, \\ Shen Yang, Liao Ning Province, China
}

\begin{abstract}
The objective of the present study was to explore the factors related to the prognosis of colorectal cancer (CRC) and to establish a prognostic model for the selection of patients who might benefit from hepatic resection for metastatic CRC. A total of 293 patients undergoing liver resection for metastatic CRC (172 males and 80 females ranging in age from 26 to 80 years) were selected and clinical, pathological and outcome data were examined in this retrospective study. The prognostic index (PI) of the patients was calculated on the basis of results of multivariate analysis. Patients were stratified into different groups, with survival curves projected according to PI. The 1-, 3-, and 5-year overall survival rates were $58.3,26.4$, and $11.3 \%$, respectively. Univariate analysis indicated that degree of primary tumor differentiation, resection margin, preoperative carcinoembryonic antigen (CEA) level, number of liver metastases, and resection of liver metastases were associated with prognosis $(P<0.05)$. In multivariate analysis, the last three factors were found to be independent prognostic factors. The resection of liver metastases was a favorable factor. Patients were classified into three groups according to PI, which differed significantly in survival rate $(\mathrm{P}<0.05)$. The individual survival rate was evaluated based on PI. Resection of hepatic colorectal metastases may produce long-term survival and cure. The proposed PI was easy to use, was highly predictive of patient outcome, and permitted categorization of patients into treatment groups.
\end{abstract}

Key words: Colorectal cancer; Liver metastasis; Prognosis

\section{Introduction}

Colorectal carcinoma (CRC) is a common malignancy of the digestive system and up to $50 \%$ of affected patients will develop metastases during the course of their disease $(1,2)$. Radical resection offers the only chance of long-term survival, with 30 to $40 \%$ of patients surviving 5 years. Recent advances in imaging modality, indication of hepatic resection, technical refinement of hepatectomy and perioperative care, together with the expansion of criteria for surgery, have increased the number of patients suitable for hepatic resection and the safety of the procedure $(3,4)$. However, the prognosis for patients with liver metastases from CRC is still poor. Because of this, only 30 to $58 \%$ of patients who undergo a curative liver resection with complete extirpation of liver metastases are alive at 5 years $(5,6)$. The present study retrospectively analyzed 293 patients subjected to resection of liver metastases in the Department of Surgery, the First Hospital of China Medical University and Shen Zhou Hospital of Shen Yang Medical College, China, from January 1993 to January 2006. Several variables were analyzed by univariate and multivariate methods to determine independent prognostic factors in order to calculate the prognostic index $(\mathrm{PI})$ and then to establish a prognostic scoring system to identify patients most likely to benefit from surgery.

\section{Patients and Methods}

\section{Patients}

A total of 293 patients with histologically proven liver metastases from CRC underwent surgical therapy in the Department of General Surgery, the First Hospital of China Medical University and Shen Zhou Hospital of Shen Yang

Correspondence: Y.F. Liu, Department of General Surgery, The First Hospital of China Medical University, Shen Yang, 110001, Liao Ning Province, China. E-mail: gre031025@gmail.com

Received April 7, 2010. Accepted September 16, 2010. Available online October 8, 2010. Published November 12, 2010. 
Medical College, from January 1993 to January 2006. The diagnosis of metastatic CRC was confirmed by histopathological assessment. Patients were considered to have resectable disease if there was local control of the primary cancer, no extrahepatic disease existed, and complete removal of all hepatic lesions was expected, leaving enough hepatic parenchyma to prevent liver failure. No ablative strategies were used along with resection in any of these patients. Intraoperative ultrasound of the liver was performed in all patients to assign the location of the lesions to anatomical structures and to rule out additional lesions in the remnant liver.

The treatment policy for synchronous liver metastases was simultaneous resection regardless of their number and extent and the location of the primary cancer. Data for these patients were extracted from the hospital database and interviews, including gender, age, vascular invasion, hepatic lymph node metastases, extrahepatic metastases, type of hepatic resection, location of the primary tumor, preoperative carcinoembryonic antigen (CEA) levels, degree of primary tumor differentiation, diameter of the largest liver metastasis, liver metastasis distribution, resection margin, number of liver metastases, resection of liver metastases, and time of diagnosis of liver metastases.

\section{Statistical analysis}

Death occurring within 30 days of the surgical procedure was defined as operative mortality. Death occurring after surgery and before discharge was defined as hospital mortality. Survival time was calculated from the date of hepatic resection to death or censored date. Patients who died of CRC were treated as event observations, and patients who died of unrelated causes and were alive at the last follow-up were treated as censored observations. Survival curves were constructed using the Kaplan-Meier method and compared by the log-rank test. Significant prognostic factors in the univariate analysis were entered into the Cox proportional hazards multiple regression model, and stepwise selection of independent prognostic variables was performed manually by significant changes in likelihood ratio. A software program (SPSS 14.0, SPSS Inc., USA) was used for the statistical analyses.

\section{Results}

\section{Patient demographics}

The 1-, 3-, and 5-year overall survival rates were 58.3, 26.4 , and $11.3 \%$, respectively. The overall survival curve is shown in Figure $1 \mathrm{~A}$.

Patients with stage III or IV colon cancer according to the classification of the International Union Against Cancer (UICC) normally received adjuvant chemotherapy after resection, but chemotherapy was not administered routinely before or after hepatic resection. Six patients who died in the hospital and 35 patients with an uneventful perioperative course who were lost to follow-up were also excluded from analysis. Thus, data of 252 patients were eligible for final analysis. The study population included 172 men (68.3\%) and 80 women (31.7\%). Median patient age was 61 years (range: 33-84 years). The primary tumor was located in the
A

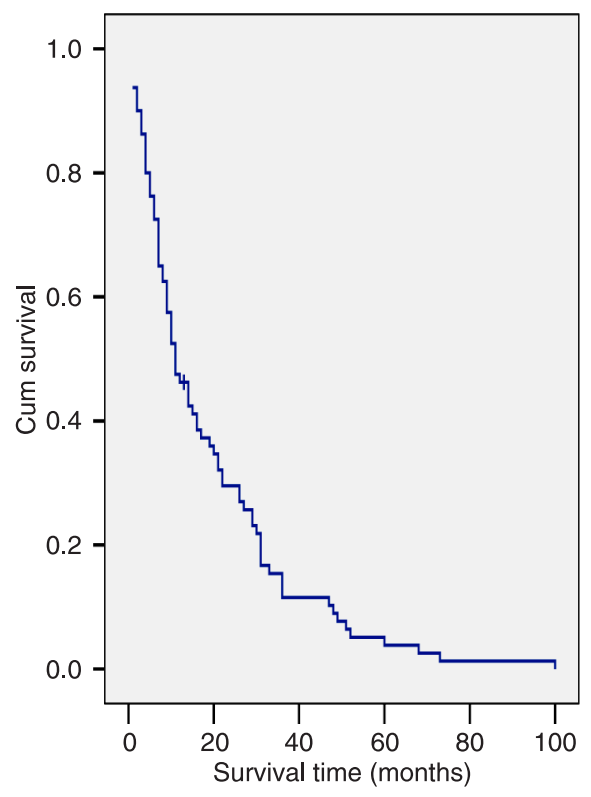

B

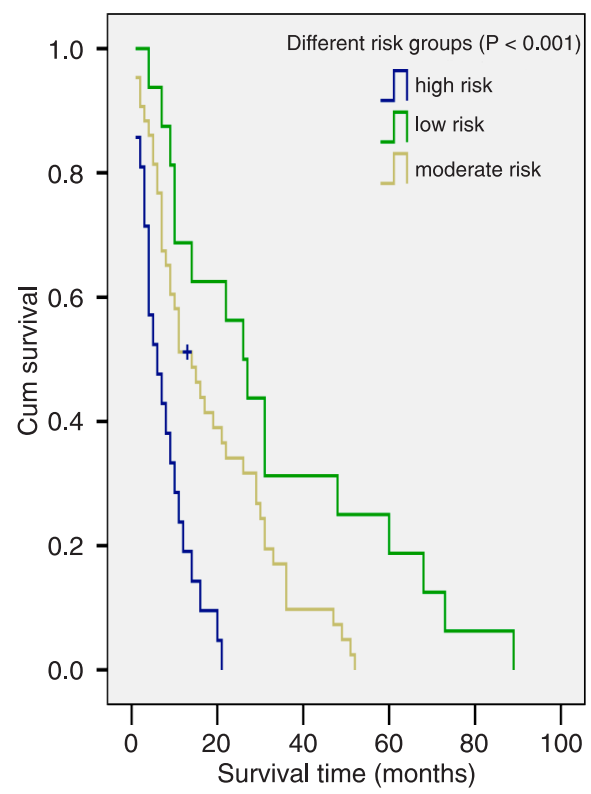

Figure 1. Overall survival curve for all patients $(A)$ and different risk groups $(B) .+=$ censored. 
colon in 146 patients $(57.9 \%)$ and in the rectum in 106 patients (42.1\%). Liver metastases were present at the time of diagnosis in 105 patients $(41.7 \%)$, whereas 147 patients $(58.4 \%)$ had metachronous hepatic lesions. Nineteen patients $(7.5 \%)$ underwent repeat liver resection. Among the 252 curative surgical procedures, 43 wedge resections $(17.1 \%), 138$ segmentectomies $(54.8 \%)$, and 71 major hepatectomies $(28.2 \%)$ were performed. Operative complications occurred in 46 patients (18.3\%). Postoperative hemorrhage, pleural effusion, wound abscess, intraabdominal abscess, bile leakage and anastomotic leakage, occurred in 9, $13,10,6,4$, and 4 patients, respectively. In 11 patients (4.4\%), a second laparotomy was required.

\section{Univariate analysis of outcome}

We analyzed the effects of 15 clinical pathologic factors on survival. Preoperative CEA level of less or more than $100 \mathrm{ng} / \mathrm{mL}(P=0.006)$, degree of primary tumor differentiation $(\mathrm{P}=$ $0.001)$, positive or negative resection margin $(P=0.007)$, more or less than 3 liver metastases $(P=0.021)$, resection of liver metastases or not $(P=0.018)$ showed a significant prognostic value for survival (Table 1).

\section{Multivariate analysis of outcome}

The prognostic factors in univariate analysis were entered into a multivariate model to identify independent predictors of long-term survival. Among the five significant variables, preoperative CEA level, number of liver metastases, and resection of liver metastases were identified as independent prognostic factors and used to calculate the PI (Figure 2). Of these, preoperative CEA levels were clearly the most influential, with an increase in the likelihood of death of 1.746 times if preoperative CEA levels were higher than $100 \mathrm{ng} / \mathrm{mL}$, followed by number of liver metastases of 3 or more (relative risk, $R R=1.432$ ), and resection of liver metastases or not represented a favorable factor $(\mathrm{RR}=$ 0.406) (Table 2, Figure 2).
Table 1. Univariate analysis of prognostic factors after resection of liver metastases from colorectal cancer.

\begin{tabular}{|c|c|c|c|c|}
\hline Variable & No. of patients & $\begin{array}{l}\text { Median survival } \\
\text { (months) }\end{array}$ & $\chi^{2}$ & $\mathrm{P}$ \\
\hline \multicolumn{5}{|l|}{ Gender } \\
\hline Male & 172 & 22.3 & & \\
\hline Female & 80 & 23.5 & 0.61 & 0.460 \\
\hline \multicolumn{5}{|l|}{ Age } \\
\hline$<60$ & 167 & 22.1 & & \\
\hline$\geq 60$ & 85 & 22.9 & 2.14 & 0.197 \\
\hline \multicolumn{5}{|l|}{ Vascular invasion } \\
\hline Negative & 230 & 27.6 & & \\
\hline Positive & 22 & 19.3 & 2.31 & 0.119 \\
\hline \multicolumn{5}{|c|}{ Hepatic lymph node metastasis } \\
\hline Negative & 246 & 26.8 & & \\
\hline Positive & 6 & 13.2 & 0.157 & 0.245 \\
\hline \multicolumn{5}{|c|}{ Extrahepatic metastases } \\
\hline Negative & 226 & 24.7 & & \\
\hline Positive & 26 & 20.5 & 3.57 & 0.067 \\
\hline \multicolumn{5}{|c|}{ Type of hepatic resection } \\
\hline Wedge & 43 & 27.4 & & \\
\hline Segmentectomy & 138 & 19.2 & & \\
\hline Hepatectomy & 71 & 23.5 & 4.29 & 0.052 \\
\hline \multicolumn{5}{|c|}{ Location of primary tumor } \\
\hline Colon & 146 & 24.1 & & \\
\hline Rectum & 106 & 23.8 & 1.634 & 0.392 \\
\hline \multicolumn{5}{|c|}{ Preoperative CEA levels (ng/mL) } \\
\hline$<100 \mathrm{ng} / \mathrm{mL}$ & 138 & 28.2 & & \\
\hline$\geq 100 \mathrm{ng} / \mathrm{mL}$ & 114 & 19.7 & 10.24 & 0.006 \\
\hline \multicolumn{5}{|c|}{ Degree of primary tumor differentiation } \\
\hline Good & 76 & 26.7 & & \\
\hline Moderate & 109 & 25.1 & & \\
\hline Poor & 67 & 20.1 & 22.54 & 0.001 \\
\hline \multicolumn{5}{|c|}{ Diameter of the largest liver metastasis } \\
\hline$<5 \mathrm{~cm}$ & 163 & 31.2 & & \\
\hline$\geq 5 \mathrm{~cm}$ & 89 & 24.6 & 3.48 & 0.069 \\
\hline \multicolumn{5}{|c|}{ Liver metastasis distribution } \\
\hline Unilobar & 185 & 33.4 & & \\
\hline Bilobar & 67 & 26.0 & 3.97 & 0.062 \\
\hline \multicolumn{5}{|l|}{ Resection margin } \\
\hline Negative & 233 & 29.4 & & \\
\hline Positive & 19 & 17.2 & 9.64 & 0.007 \\
\hline \multicolumn{5}{|c|}{ No. of liver metastases } \\
\hline$\leq 3$ & 203 & 38.4 & & \\
\hline$>3$ & 49 & 24.3 & 4.69 & 0.021 \\
\hline \multicolumn{5}{|c|}{ Resection of liver metastases } \\
\hline Yes & 143 & 29.5 & & \\
\hline No & 109 & 24.1 & 5.23 & 0.018 \\
\hline \multicolumn{5}{|c|}{ Time of diagnosis of liver metastases } \\
\hline Synchronous & 105 & 30.3 & & \\
\hline Metachronous & 147 & 23.7 & 0.51 & 0.532 \\
\hline
\end{tabular}

$\mathrm{CEA}=$ carcinoembryonic antigen . 


\section{Calculation of PI}

The PI equation was constructed including all significant variables and coefficients from Table 2 as follows: $\mathrm{PI}=$ $(0.349 \times$ number of liver metastases $)+(0.751 \times$ preoperative CEA levels) - (0.817 $\times$ resection of liver metastases). In this equation the value of each variable was scored as 1 or 2: liver metastasis resection, 1 ; no liver metastasis resection, 2; less than 3 liver metastases, 1; more than 3 liver metastases, 2; preoperative CEA level of less than 100 $\mathrm{ng} / \mathrm{mL}, 1$; preoperative CEA level of more than $100 \mathrm{ng} / \mathrm{mL}$, 2. The maximum $P I$ value is 1.383 , and the minimum value is -0.534 . With the upper and lower quartile of $\mathrm{PI}$, patients were divided into three risk groups and the differences in survival between groups were significant by the KruskalWallis $\mathrm{H}$ test (Table 3, Figure 1B).

\section{Calculation of individual survival}

To estimate the expected survival rate of each individual, we first calculated the average level of the t-year survival rate $\mathrm{S}(\mathrm{t})$. In this study, we used the median prognostic index $\mathrm{M}$ as a benchmark, and individual's $\mathrm{RR}=\exp (\mathrm{PI}-\mathrm{M})$. Thus, the individual t-year survival rate is $S(t)^{R R}$. Next, we randomly selected four individuals to calculate the expected survival rate compared to the benchmark (Table 4).

\section{Discussion}

The liver is the most common site of distant metastases from CRC. Resection remains the only chance of cure for patients with hepatic colorectal metastases, resulting in prolonged survival compared to patients treated with palliative

Table 2. Multivariate analysis of prognostic factors after resection of synchronous liver metastases from colorectal cancer.

\begin{tabular}{lccccccc}
\hline Variable & $\beta$ & Wald $\chi^{2}$ & $P$ & $\begin{array}{c}\text { Relative risk } \\
\text { (RR) }\end{array}$ & \multicolumn{2}{c}{ RR (95\%Cl) } \\
\cline { 6 - 7 } & & & & & & Lower & Upper \\
\hline Number of liver metastases & 0.349 & 5.542 & 0.019 & 1.432 & 1.062 & 1.931 \\
Preoperative CEA levels & 0.751 & 4.149 & 0.002 & 1.746 & 1.021 & 2.985 \\
Resection of liver metastases & -0.817 & 4.526 & 0.033 & 0.406 & 0.177 & 0.934 \\
Gender & 0.126 & 0.096 & 0.757 & 1.134 & 0.512 & 2.515 \\
Age & -0.425 & 1.578 & 0.209 & 0.654 & 0.337 & 1.269 \\
Vascular invasion & 0.284 & 0.458 & 0.498 & 1.328 & 0.584 & 3.020 \\
Hepatic lymph node metastasis & 0.384 & 1.094 & 0.296 & 1.468 & 0.715 & 3.015 \\
Extrahepatic metastases & 0.080 & 0.021 & 0.886 & 1.084 & 0.362 & 3.247 \\
Type of hepatic resection wedge & 0.994 & 1.989 & 0.158 & 2.701 & 0.679 & 10.744 \\
Location of primary tumor & 0.036 & 0.094 & 0.759 & 1.037 & 0.824 & 1.305 \\
Degree of primary tumor differentiation & -0.185 & 0.746 & 0.388 & 0.831 & 0.547 & 1.264 \\
Diameter of the largest liver metastasis & 0.329 & 0.252 & 0.616 & 1.389 & 0.385 & 5.016 \\
Liver metastasis distribution & 0.125 & 0.017 & 0.895 & 1.133 & 0.177 & 7.236 \\
Resection margin & 0.188 & 0.128 & 0.720 & 1.206 & 0.432 & 3.372 \\
Time of diagnosis of liver metastases & 0.092 & 0.035 & 0.852 & 1.096 & 0.418 & 2.875 \\
\hline
\end{tabular}

$\mathrm{CEA}=$ carcinoembryonic antigen .

Table 3. Survival rate of the different risk groups (Kruskal-Wallis $\mathrm{H}$ test).

\begin{tabular}{|c|c|c|c|c|c|c|c|c|}
\hline \multirow[t]{2}{*}{ PI classification } & \multirow[t]{2}{*}{ Median } & \multirow[t]{2}{*}{$\mathrm{PI}$} & \multirow[t]{2}{*}{ Number of cases } & \multicolumn{3}{|c|}{ Survival rate $(\%)$} & \multirow[t]{2}{*}{$\chi^{2}$} & \multirow[t]{2}{*}{$\mathrm{P}$} \\
\hline & & & & 1 year & 3 years & 5 years & & \\
\hline Low risk & 31 & $P \leq 0.016$ & 63 & 74.9 & 34.5 & 20.8 & 27.3 & $<0.00$ \\
\hline Moderate risk & 15 & $0.016<\mathrm{PI}<1.383$ & 123 & 55.7 & 24.3 & 10.3 & & \\
\hline High risk & 6 & $\mathrm{PI} \geq 1.383$ & 66 & 32.3 & 1.7 & 0 & & \\
\hline
\end{tabular}



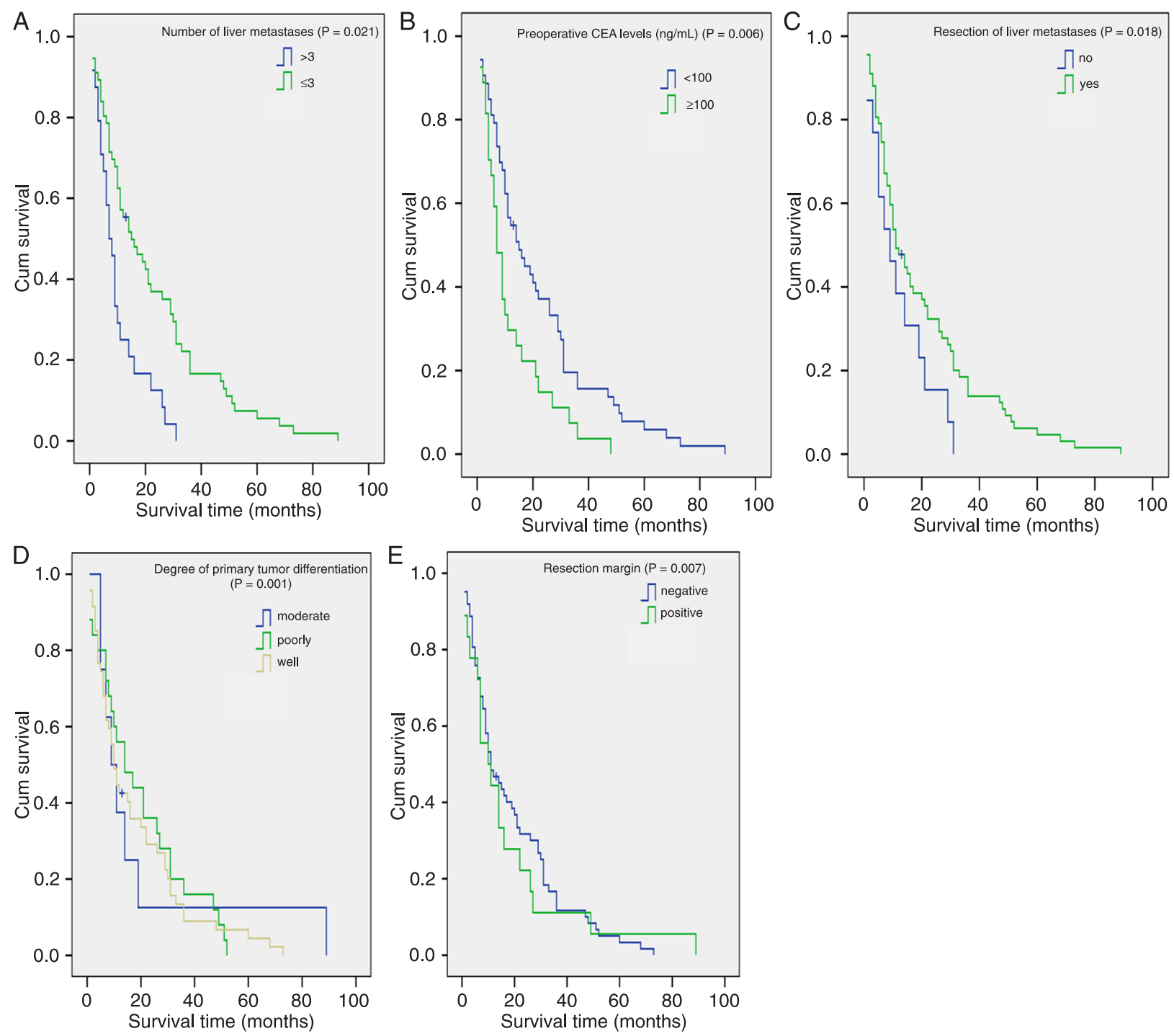

Figure 2. Survival curve according to five significant variables. + = censored.

chemotherapy (7-9). The safety of major hepatic resection has been demonstrated in many institutions, encouraging surgeons to pursue more extensive resections (10-13). This has resulted in increasing complexity of the surgical approach. Resections involving the removal of more than two-thirds of the liver parenchyma are common, as are resections of more than four hepatic metastases (14-16). Advances in surgical technique and perioperative care, such as portal vein embolization, have enabled a more radical approach to the treatment of CRC liver metastases and extended the indications for surgical therapy. Thus, there is an ongoing need for a system to be used for the scrutiny of such invasive therapy.

In the 1980's, two staging systems were developed by Gennari et al. $(17,18)$. These systems were based on the degree and extent of metastatic tumors and not on factors

Table 4. t-year survival rate of four selected individuals.

\begin{tabular}{|c|c|c|c|c|c|}
\hline \multirow[t]{2}{*}{$\begin{array}{l}\text { Random } \\
\text { individual }\end{array}$} & \multirow[t]{2}{*}{ PI } & \multirow[t]{2}{*}{$\mathrm{RR}$} & \multicolumn{3}{|c|}{$\begin{array}{l}\text { Expected t-year } \\
\text { survival rate }(\%)\end{array}$} \\
\hline & & & 1 year & 3 years & 5 years \\
\hline 1 & 1.383 & 2.61 & 24.5 & 3.9 & 0.5 \\
\hline 2 & 0.632 & 1.29 & 49.9 & 20.3 & 7.7 \\
\hline Benchmark & 0.425 & 1.0 & 58.3 & 29.1 & 13.7 \\
\hline 3 & 0.217 & 0.81 & 64.5 & 36.7 & 19.9 \\
\hline 4 & -0.534 & 0.38 & 81.3 & 62.3 & 46.7 \\
\hline
\end{tabular}

$\mathrm{PI}=$ prognostic index; $\mathrm{RR}=$ relative risk 
related to primary $\mathrm{CRC}(17,18)$. These staging systems were based on a multivariate survival analysis reflecting prognosis but using 7 factors. Thus, all of the factors must be explored to determine the stage, which may make it difficult to use these staging systems. Thus, a prognostic system might be helpful to grade patients' risk and to be used to tailor their further management. We have chosen a novel approach to develop a prognostic system based on variables that were derived from significant independent prognostic factors for consideration of liver surgery.

The prognostic index model presented here can improve the accuracy of patient selection for surgery and be used to allocate patients to combined treatment modalities. Moreover, the $\mathrm{P}$ values for high risk vs moderate risk groups and moderate risk vs low risk groups are significant.

The PI was calculated from an equation based on variables and their correlation coefficients and related to high, moderate and poor risk groups. Three groups with different prognoses were identified among all candidates for liver surgery.

Although liver resection improved survival prospects in all patients regardless of their prognosis, none of the patients assigned to the high risk group were alive at 5-year followup. From our results, it is obvious that patients in the high risk group have very poor outcomes, and resection without additional effective adjuvant therapy is highly questionable. Patients in the moderate risk group have a much more guarded prognosis, and resection should be planned in the context of adjuvant therapies. Patients in the low risk group have a highly favorable outcome, and surgical resection is undoubtedly a rational therapy. Moreover, extensive preoperative staging involving positron emission tomography and magnetic resonance imaging might be performed in patients who are in the high risk group, but are otherwise suitable for major liver resection (19-22).

Extrahepatic extension, such as extrahepatic metastases, extrahepatic invasion, local recurrence of the primary cancer, and hepatic node metastases, has been analyzed as a whole in most previous studies. Patients with these factors have long been considered to be contraindicated for hepatectomy because of their negative outcome. However, lung metastases, intraperitoneal dissemination, and local recurrence have gradually gained acceptance for resection

\section{References}

1. Khatri VP, Petrelli NJ, Belghiti J. Extending the frontiers of surgical therapy for hepatic colorectal metastases: is there a limit? J Clin Oncol 2005; 23: 8490-8499.

2. Benson $A B$ III. Epidemiology, disease progression, and economic burden of colorectal cancer. J Manag Care Pharm 2007; 13: S5-S18.

3. Folprecht G, Grothey A, Alberts S, Raab HR, Kohne $\mathrm{CH}$. Neoadjuvant treatment of unresectable colorectal liver metastases: correlation between tumour response and resec- in some institutions because a favorable prognosis can be anticipated if the tumors are removed completely $(23,24)$. Many ablative methods have been proposed for the treatment of liver tumors that are not suitable for resection. For instance, cryoablation and radiofrequency ablation show the greatest promise as treatment for metastatic colorectal cancer. Although unlikely to be curative for large lesions, it is possible that these ablative techniques may produce complete destruction of smaller metastases. An ever-moreaggressive approach is being undertaken based on the improving safety of hepatic resection and as a result of the inability of other therapies to produce long-term survival. It is also clear that systemic chemotherapy may have the greatest impact in the adjuvant setting where residual disease is minimal and microscopic. In a recent study of combined regional and systemic adjuvant chemotherapy, patients in the high risk group benefited most from such aggressive adjuvant chemotherapy.

The application of the Cox model to select the variables that influence long-term survival, to calculate the individual $\mathrm{PI}$ and then to stratify the patients into different groups is widely used in clinical research. Liu et al. (25) stated that the Cox model has practical significance only when the entire $\mathrm{PI}$ is stratified into different groups according to the estimated survival rate. Some studies have applied the PI to nasopharyngeal and endometrial cancer, showing that the $\mathrm{Pl}$ is of good practical use (26).

The present study was based on Cox regression analysis of the $\beta$ value and significant prognostic factors to calculate the PI for each patient. With PI of the upper and lower quartiles for the sector, patients were divided into three groups. The results showed that there is a large difference in survival rates, suggesting that $\mathrm{PI}$ is of clinical and practical value. Obviously, PI could predict long-term patient survival, facilitating the choice of treatment for clinical reference.

\section{Acknowledgments}

The authors would like to thank Song Wang (Shen Yang Environmental Protection Bureau) for assistance with the statistical analysis.

tion rates. Ann Oncol 2005; 16: 1311-1319.

4. Chung KY, Saltz LB. Antibody-based therapies for colorectal cancer. Oncologist 2005; 10: 701-709.

5. Choti MA, Sitzmann JV, Tiburi MF, Sumetchotimetha W, Rangsin R, Schulick RD, et al. Trends in long-term survival following liver resection for hepatic colorectal metastases. Ann Surg 2002; 235: 759-766.

6. Abdalla EK, Vauthey JN, Ellis LM, Ellis V, Pollock R, Broglio $\mathrm{KR}$, et al. Recurrence and outcomes following hepatic re- 
section, radiofrequency ablation, and combined resection/ ablation for colorectal liver metastases. Ann Surg 2004; 239: 818-825.

7. Kerr DJ, McArdle CS, Ledermann J, Taylor I, Sherlock DJ, Schlag PM, et al. Intrahepatic arterial versus intravenous fluorouracil and folinic acid for colorectal cancer liver metastases: a multicentre randomised trial. Lancet 2003; 361: 368-373.

8. Yuste AL, Aparicio J, Segura A, Lopez-Tendero P, Girones R, Perez-Fidalgo JA, et al. Analysis of clinical prognostic factors for survival and time to progression in patients with metastatic colorectal cancer treated with 5-fluorouracil-based chemotherapy. Clin Colorectal Cancer 2003; 2: 231-234.

9. Lorenz M, Muller HH. Randomized, multicenter trial of fluorouracil plus leucovorin administered either via hepatic arterial or intravenous infusion versus fluorodeoxyuridine administered via hepatic arterial infusion in patients with nonresectable liver metastases from colorectal carcinoma. J Clin Oncol 2000; 18: 243-254.

10. Yamada H, Katoh H, Kondo S, Okushiba S, Morikawa T. Mesenteric lymph nodes status influencing survival and recurrence pattern after hepatectomy for colorectal liver metastases. Hepatogastroenterology 2002; 49: 1265-1268.

11. Ercolani G, Grazi GL, Ravaioli M, Cescon M, Gardini A, Varotti G, et al. Liver resection for multiple colorectal metastases: influence of parenchymal involvement and total tumor volume, vs number or location, on long-term survival. Arch Surg 2002; 137: 1187-1192.

12. Weber SM, Jarnagin WR, DeMatteo RP, Blumgart LH, Fong Y. Survival after resection of multiple hepatic colorectal metastases. Ann Surg Oncol 2000; 7: 643-650.

13. Jarnagin WR, Gonen M, Fong $Y$, DeMatteo RP, Ben-Porat L, Little S, et al. Improvement in perioperative outcome after hepatic resection: analysis of 1,803 consecutive cases over the past decade. Ann Surg 2002; 236: 397-406.

14. Scheele J, Stang R, Altendorf-Hofmann A, Paul M. Resection of colorectal liver metastases. World J Surg 1995; 19: 59-71.

15. Gayowski TJ, Iwatsuki S, Madariaga JR, Selby R, Todo S, Irish W, et al. Experience in hepatic resection for metastatic colorectal cancer: analysis of clinical and pathologic risk factors. Surgery 1994; 116: 703-710.

16. Nordlinger B, Guiguet M, Vaillant JC, Balladur P, Boudjema
$\mathrm{K}$, Bachellier $\mathrm{P}$, et al. Surgical resection of colorectal carcinoma metastases to the liver. A prognostic scoring system to improve case selection, based on 1568 patients. Association Francaise de Chirurgie. Cancer 1996; 77: 1254-1262.

17. Gennari L, Doci R, Bignami P, Bozzetti F. Surgical treatment of hepatic metastases from colorectal cancer. Ann Surg 1986; 203: 49-54.

18. Gennari L, Doci R, Bozzetti F, Bignami P. Proposal for staging liver metastases. Recent Results Cancer Res 1986; 100 : 80-84.

19. Strasberg SM, Dehdashti F, Siegel BA, Drebin JA, Linehan $D$. Survival of patients evaluated by FDG-PET before hepatic resection for metastatic colorectal carcinoma: a prospective database study. Ann Surg 2001; 233: 293-299.

20. Zealley IA, Skehan SJ, Rawlinson J, Coates G, Nahmias $\mathrm{C}$, Somers S. Selection of patients for resection of hepatic metastases: improved detection of extrahepatic disease with FDG pet. Radiographics 2001; 21 (Spec. No.): S55-S69.

21. Strasberg SM, Siegal BA. Survival of patients staged by FDG-PET before resection of hepatic metastases from colorectal cancer [letter]. Ann Surg 2002; 235: 308-310.

22. Rohren EM, Paulson EK, Hagge R, Wong TZ, Killius J, Clavien PA, et al. The role of F-18 FDG positron emission tomography in preoperative assessment of the liver in patients being considered for curative resection of hepatic metastases from colorectal cancer. Clin Nucl Med 2002; 27: 550-555.

23. Headrick JR, Miller DL, Nagorney DM, Allen MS, Deschamps C, Trastek VF, et al. Surgical treatment of hepatic and pulmonary metastases from colon cancer. Ann Thorac Surg 2001; 71: 975-979.

24. Elias D, Ouellet JF, Bellon N, Pignon JP, Pocard M, Lasser P. Extrahepatic disease does not contraindicate hepatectomy for colorectal liver metastases. Br J Surg 2003; 90: 567574.

25. Liu Q, Jin PH, Da-Wei HE. A study of estimating the survival rate of Cox's model classed by PV. Chinese Health Stat 1997; 14: 4-6.

26. Hua ZJ, Hong MH, Luo DH, Qiu Z, Guo L, Zhang GY. Multivariable analysis of prognostic predictors for 406 patients with nasopharyngeal carcinoma [J]. Chinese Oncol Clin 2005; 32: 435-438. 